\title{
Maternal Perception of School-age Children's Weight in Piedras Negras, Coahuila: A Pilot Study
}

Melisa de los Santos-Tonche ${ }^{1}$, Regina Alonso-Tovar', Juan Parra-Ávila², María del Carmen Portillo-Téllez ${ }^{2}$, Juan Felipe Mayo-Carrillo ${ }^{2}$ and Felipe Javier Uribe-Salas ${ }^{2, *}$

${ }^{1}$ Universidad Vizcaya de las Américas, Campus Piedras Negras, Coahuila, México

${ }^{2}$ El Colegio de la Frontera Norte, Región Noreste, Piedras Negras, Coahuila, México

\section{Abstract}

Aim: To analyze mother's perception of children's weight and its relationship with sex, age, schooling level, weight, and perimeters of hip and waist, as well as concordance analysis between mother's perception of BMI categories and actual BMI categories and the evaluation of body size satisfaction.

Methods: A cross-sectional study was conducted including all students from fourth to sixth grades in an elementary school. Anthropometric measurements as weight and high were taken. Body mass index percentiles and actual weight categories were obtained. To evaluate perception of body image the CBIS template was used. Descriptive and inferential analysis of results, were performed.

Results: A total of 164 children were studied being women 53.7 percent. Maternal perception of children's body weight showed high magnitude of perceived children in normal weight. Significant difference was found between maternal perception of children's weight and the variable of sex. Concordance between mother's perception of BMI and actual BMI was of 0.45 and 0.37 for girls and 0.53 for boys. Body size satisfaction perceived by mothers was high and occurred mainly at expenses of the perception of children's normal weight.

Discussion: The results suggest that mothers tend to classified correctly children's body weight regarding the category of normal weight and perceived in higher proportion overweight among girls and obesity among boys. Frequency of body size satisfaction perceived by mothers was high and occurred mainly at expenses of normal weight. Mothers underestimate their children's weight in cases of overweight and obesity and overestimate those with low weight.

\section{Introduction}

Body image is a subjective, dynamic and multidimensional concept that encompasses perceptions, thoughts and feelings that the person has about his body or that of others [1]. Perception of body image depends on personal (personality, self-esteem), interpersonal (family, friends, messages from the media), biological (genetic, body mass index, pathologies) and cultural (values and social norms) characteristics [2]. Each aspect of body image is addressed by different instruments. The perceptual component of body image, for example, refers to the "body size" such that subjective satisfaction or dissatisfaction with body image can be evaluated using scales of body figures [1,2]. During the last 15 years different strategies have been developed to assess the perception of body weight and dissatisfaction with body image in children, adolescents and adults. The construction of a scale of body figures have the advantage of being quick to apply and visual image is less abstract than a question about body volume and does not require sophisticated equipment for its application.

Regarding school-age children, different silhouettes have been designed to assess body image [3-5]. Furthermore, it has been documented that dissatisfaction with body image increases in prepubertal age accompanied by weight loss strategies and eating disorders [6-8]. Likewise, validity and reproducibility of body figures scale composed of seven silhouettes of pre-adolescent girls and boys that range from the emaciated to the obese figure [7] have been performed. Notwithstanding the foregoing, the relationship between children's BMI and the design of body figures had not been established until Truby et al. [9] developed a template with drawings of body figures that were based on photographs of children with different percentiles of BMI. Seven figures were developed based on a

\section{Publication History:}

Received: March 05, 2020

Accepted: May 19, 2020

Published: May 21, 2020

\section{Keywords:}

Body image, Size perception, Child, Body size satisfaction, Piedras Negras scale of percentiles ranging from the 3 rd percentile, through the 10th, 25th, 50th, 75th, 90th, to the 97th percentile. The authors conclude that the body image scale for children (CBIS) provides an acceptable measurement of body weight perception, both in girls and boys. It also allows assessing the dissatisfaction of body volume in children.

The perception of the body weight of the children by fathers, especially by mothers, has also been analyzed. Parents' knowledge of both the low weight of children and overweight and obesity has consequences for children's health due to the possibility of establishing preventive measures at an early age. However, it has been reported by studies done in different countries that a high proportion of parents do not recognize excess of weight in themselves and neither among their children [10-13]. Reasons have been given to explain this inability of parents to recognize that there is excess weight in their children such as refusal to admit the existence of problems with weight or a loss of sensitivity in the perception of excess weight due to that this is so frequent that it has become a phenomenon that is perceived as normal [14]. The purpose of this work was to evaluate a) the distribution of mother's perception of children's BMI categories and its relationship

"Corresponding Author: Dr. Felipe J. Uribe Salas, El Colegio de la Frontera Norte. Calle Jalisco 1505, Colonia Nísperos, Piedras Negras, Coahuila, México. C.P. 26020. Tel: 878782 7207; E-mail: fjuribe@colef.mx

Citation: Santos-Tonche M, Alonso-Tovar R, Parra-Ávila J, Portillo-Téllez MC, Mayo-Carrillo JF, et al. (2020) Maternal Perception of School-age Children's Weight in Piedras Negras, Coahuila. A Pilot Study. Int J Pediatr Neonat Care 6: 166. doi: https://doi.org/10.15344/2455-2364/2020/166

Copyright: (C) 2020 Santos-Tonche et al. This is an open-access article distributed under the terms of the Creative Commons Attribution License, which permits unrestricted use, distribution, and reproduction in any medium, provided the original author and source are credited. 
Citation: Santos-Tonche M, Alonso-Tovar R, Parra-Ávila J, Portillo-Téllez MC, Mayo-Carrillo JF, et al. (2020) Maternal Perception of School-age Children's Weight in Piedras Negras, Coahuila. A Pilot Study. Int J Pediatr Neonat Care 6: 166. doi: https://doi.org/10.15344/2455-2364/2020/166

Page 2 of 5

with sex, age, schooling level, weight, and hip and waist perimeters, of the studied children $b$ ) concordance between mother's perception of BMI categories and actual BMI categories, and c) the comparison of perceived and ideal BMI categories discrepancy to evaluate body size satisfaction, in the context of a City sited in the Norther border of Coahuila State in wide contact with the population of the southern region of Texas State in the United States.

\section{Methods}

\section{Desing and study population}

A cross-sectional pilot study was conducted during November, 2016 , that included all students from fourth, fifth and sixth grades in an elementary school in Piedras Negras City. Mothers were also included for this study. In order to have access to study of children and their mothers, permission from the authorities of the school institution was requested and an informed consent letter was designed to be signed by the parents or guardians of the children and besides, confidentiality of information obtained was assured. The study protocol was presented to the Research Committee of El Colegio de la Frontera Norte.

\section{Anthropometric measurements}

Standardization in taking measurements was made with the Izak method [15]. Measurements were made in children without shoes and light clothes. The weight of the children was taken with the scale (Seca 803 ) considering an accuracy of 0.1 kilograms. For children's size the stadiometer (Dry 213) was utilized with an accuracy of $0.1 \mathrm{~cm}$.

\section{Perception of body image}

We used the instrument of "children's body image scale" (CBIS) template composed of 7 figures based on photographs of boys and girls with different BMI percentiles in such a way that it allows recoding the values to build the categories of low weight, normal weight, overweight and obesity, according to the classification of the Centers for Disease Control (9) and defined as actual BMI categories. This scale was evaluated in its reproducibility to be used with international standards [16]. To assess mothers' perception of children's weight they were asked to select on the scale of figures the one that represented the current body volume of the children and defined as perceived BMI categories. Mothers were also asked in a second question to select the ideal body figure that mothers would like their children to have defined as ideal BMI categories.

\section{Body mass index percentiles and actual weight}

To calculate BMI percentiles, we used the program designed by Romero [17] to calculate percentiles of weight, height and BMI stratified by sex and age (between 2 and 20 years). The program is organized to work with the growth curves elaborated by the CDC so it will be used at the following cut-off points: low weight below the 5 th percentile, normal weight between the 5 th and 85 th percentiles, overweight between the 85 th percentiles and 95 and obesity above the 95th percentile.

\section{Analysis plan}

Descriptive statistics were made by sex, age, schooling grade and classifications of BMI percentiles and of mother's perception of body figures. In order to analyze variations of perceived BMI categories, their association with sex and schooling grade of the children was evaluated using the Chi2 test; to evaluate age the ANOVA test was used; and for the distribution of mean ranks of waist, hip and body mass index measurements, the non-parametric Kruskal-Wallis test was used. Analysis of global concordance between actual BMI categories and mother's perception of BMI categories, also stratifying by sex, was made using the weighted Kappa index following the method proposed by Sklo and Nieto [18]. Body size satisfaction was evaluated by contrasting perceived BMI and ideal BMI categories, according to Truby et al. [9]. In order to evaluate a comparison of perceived and ideal discrepancy the variable of body size satisfaction was constructed which categories were a) underestimation, b) same size and d) overestimation. This variable was evaluated in relation with indicators of body size as weight, waist, hip, and percentiles of BMI though a non-parametric Kruskal-Wallis test.

\section{Results}

A total of 164 children were studied, of which slightly more than half were girls (53.7\%). Age average was 10.3 years old with the highest frequency at nine years with $33.5 \%$, followed by the children of ten and eleven years old with $31.7 \%$ and $27.4 \%$, respectively. The distribution of children by schooling grade was very similar to approximately one third per level (33.5\%, 29.5\% and 33.5\% for grades four through six). There were no significant differences by sex in average of age, weight, height and percentage of BMI (data no shown).

The results in table 1 show the relationship between maternal perception of the child's weight (perceived BMI categories) and variables of sex, schooling grade, age average and mean rank of waist and hip perimeters as well as the children's BMI. A significant difference was found between maternal perception of children's weight and the variable of sex, observing a greater proportion in the perception of overweight among women and obesity among men. No differences were found by schooling grade level and age average. However, average ranges of the distribution of weight and perimeters of waist and hip were statistically significant.

Table 2 shows the relationship between actual BMI categories and mother's perception of children's BMI categories. It can be seen that low weight and normal weight categories have higher concordance rates of $69.2 \%$ and $77.4 \%$ in contrast to the overweight and obesity categories in which the concordance rates were lower of $26.1 \%$ and $31.8 \%$, respectively. In women, a greater proportion in maternal perception of overweight was found of 35.7 with respect to the global proportion that was 26.1 , and also the absence of perception of obesity stands out. In the case of men, a low proportion in the maternal perception of overweight of 11.1 stands out, but a higher perception of obesity of 58.3. These results are reflected in the weighted concordance indexes that were of 0.459 for the overall calculation and 0.376 for women and 0.53 for men.

Body size satisfaction was expressed by the discrepancy between perceived BMI and ideal BMI categories. Global results in table 3 show an underestimation of body size in 16.5 percent $\left(27 / 164^{\star} 100\right)$, an overestimation of 14.6 percent $\left(24 / 164^{*} 100\right)$ and same size in 68.9 percent $\left(113 / 164^{\star} 100\right)$. Concordant perception between perceived and ideal BMI categories was performed to expenses of the perception of normal weight in 92.9 percent of concordant cases (105/113). However, high proportion of mothers overestimated their children's BMI especially in categories of low weight since 23 of 30 children were classified by mother's ideal perception as normal weight, representing 
Citation: Santos-Tonche M, Alonso-Tovar R, Parra-Ávila J, Portillo-Téllez MC, Mayo-Carrillo JF, et al. (2020) Maternal Perception of School-age Children's Weight in Piedras Negras, Coahuila. A Pilot Study. Int J Pediatr Neonat Care 6: 166. doi: https://doi.org/10.15344/2455-2364/2020/166

Page 3 of 5

\begin{tabular}{|c|c|c|c|c|c|}
\hline Variables & Low weight n(\%) & Normal n(\%) & Over weight n(\%) & Obesity n(\%) & $\mathrm{p}$ value \\
\hline \multicolumn{6}{|l|}{ Sex } \\
\hline Female & $15(17.5)$ & $61(69.3)$ & $11(12.5)$ & $1(0.01)$ & \\
\hline Male & $15(19.7)$ & $48(63.1)$ & $3(0.04)$ & $10(13.2)$ & \\
\hline Both female and male & $30(18.2)$ & $109(66.4)$ & $14(8.5)$ & $11(6.7)$ & $0.005^{\mathrm{a}}$ \\
\hline \multicolumn{6}{|l|}{ School grade } \\
\hline $4^{\circ}$ & $13(23.6)$ & $36(65.4)$ & $5(9.0)$ & $1(1.8)$ & \\
\hline $5^{\circ}$ & $9(16.6)$ & $36(66.6)$ & $5(9.2)$ & $4(7.4)$ & \\
\hline $6^{\circ}$ & $8(14.5)$ & $37(67.2)$ & $4(7.2)$ & $6(10.9)$ & $0.547^{\mathrm{a}}$ \\
\hline Age (average and SD) & $10.2(0.97)$ & $10.4(1.01)$ & $10.3(0.66)$ & $10.9(0.86)$ & $0.274^{\mathrm{b}}$ \\
\hline Weight (mean rank) & 40.3 & 82.3 & 131.0 & 137.2 & $<0.001^{c}$ \\
\hline Wasist(mean rank) & 38.7 & 80.9 & 138.5 & 146.3 & $<0.001^{\mathrm{c}}$ \\
\hline Hip (mean rank) & 41.7 & 81.1 & 137.3 & 138.2 & $<0.001^{\mathrm{c}}$ \\
\hline
\end{tabular}

Table 1: Maternal perception of children's weight and its relationship with sex, schooling grade, age, weight and circumferences

of waist and hip from the studied children.

${ }^{\mathrm{a}} \mathrm{Chi}$ square test; ${ }^{\mathrm{b}} \mathrm{ANOVA}$; ${ }^{\mathrm{c}} \mathrm{Kruskal}-$ Wallis test.

\begin{tabular}{|c|c|c|c|c|c|}
\hline Variable & Low weight $\mathrm{n}(\%)$ & Normal n(\%) & Over weight n(\%) & Obesity n(\%) & Kappa index ${ }^{\mathrm{a}}$ \\
\hline \multicolumn{6}{|c|}{ Maternal perception (all) } \\
\hline Lowweight & $9(69.2)$ & $21(19.8)$ & 0 & 0 & \\
\hline Normal & $4(30.8)$ & $82(77.4)$ & $15(65.2)$ & $8(36.4)$ & \\
\hline Overweight & 0 & $1(0.9)$ & $6(26.1)$ & $7(31.8)$ & \\
\hline Obesity & 0 & $2(1.9)$ & $2(8.7)$ & $7(31.8)$ & \\
\hline Total & 13 & 106 & 23 & 22 & 0.4599 \\
\hline \multicolumn{6}{|c|}{ Maternal perception (girls) } \\
\hline Lowweight & $4(66.7)$ & $11(19.0)$ & 0 & 0 & \\
\hline Normal & $2(33.3)$ & $46(79.3)$ & $8(57.1)$ & $5(50.0)$ & \\
\hline Overweight & 0 & $1(1.7)$ & $5(35.7)$ & $5(50.0)$ & \\
\hline Obesity & 0 & 0 & $1(7.1)$ & 0 & \\
\hline Total & 6 & 58 & 14 & 10 & 0.3769 \\
\hline \multicolumn{6}{|c|}{ Maternal perception (boys) } \\
\hline Lowweight & $5(71.4)$ & $10(20.8)$ & 0 & 0 & \\
\hline Normal & $2(28.6)$ & $36(75.0)$ & $7(77.8)$ & $3(25.0)$ & \\
\hline Overweight & 0 & 0 & $1(11.1)$ & $2(16.7)$ & \\
\hline Obesity & 0 & $2(4.2)$ & $1(11.1)$ & $7(58.3)$ & \\
\hline Total & 7 & 48 & 9 & 12 & 0.530 ฯ \\
\hline
\end{tabular}

Table 2: Relationship between actual BMI categories and mothers' perception of BMI categories expressed in global terms and stratified by sex.

${ }^{a}$ Weighted Kappa index; $\uparrow \mathrm{p} \leq 0.001$ Chi square test.

\begin{tabular}{|l|l|l|l|l|l|}
\hline Variable & Low weight $\mathrm{n}(\%)$ & Normal $\mathrm{n}(\%)$ & Over weight $\mathrm{n}(\%)$ & Obesity $\mathrm{n}(\%)$ & Total \\
\hline Ideal perception & & & & & \\
\hline Low weight & $7(23.3)$ & $3(2.8)$ & 0 & 0 & 10 \\
\hline Normal & $23(76.7)$ & $105(96.3)$ & $13(92.9)$ & $11(100)$ & 152 \\
\hline Overweight & 0 & $1(0.9)$ & $1(7.1)$ & 0 & 2 \\
\hline Obesity & 0 & 0 & 0 & 0 & 0 \\
\hline Total & 30 & 109 & 14 & 11 & 164 \\
\hline
\end{tabular}

Table 3: Body size satisfaction by contrasting mothers' perception of children's weight versus ideal perception of weight. 
Citation: Santos-Tonche M, Alonso-Tovar R, Parra-Ávila J, Portillo-Téllez MC, Mayo-Carrillo JF, et al. (2020) Maternal Perception of School-age Children's Weight in Piedras Negras, Coahuila. A Pilot Study. Int J Pediatr Neonat Care 6: 166. doi: https://doi.org/10.15344/2455-2364/2020/166

Page 4 of 5

95.8 percent of overestimated cases $(23 / 24)$. On the other hand, high levels of underestimation by mother's ideal perception were found in categories of overweight (48.1 percent or 13/27) and obesity (40.7 percent or 11/27).

Results of the relationship between the variable of body size satisfaction and indicators of actual body size as weight, waist, hip, and percentiles of BMI, are presented in table 4. Interesting, along all indicators of actual body size, underestimation of mother's perception has the highest magnitudes of mean rank along all variables analyzed following by magnitudes of the same-size category and the lowest magnitudes were found in the overestimation category, being this results statistically significant.

\section{Discussion}

It has been recently reported that the use of silhouette scales to identify children's body weight by mothers may be more accurate compared to the use of traditional categorical weight-labeling methods [19]. In the present study maternal perception of children's body weight using silhouette scales showed a high magnitude of perceived children in normal weight category and fewer percentages in categories of underweight, overweight and obesity. Leppers et al. [20] reported similar results to those performed in this work studying Dutch children aged 9 to 10 years using the CBIS template with the exception of maternal perception of BMI in obesity category with a low magnitude of 0.64 percent as well as higher percentage in normal weight category ( 75.9 percent).

In this study maternal perception of children's BMI categories was related with children's sex suggesting that mothers perceive in higher proportion overweight among girls and obesity among boys. Although Maynard et al. [21] evaluated maternal perception of weight status assessed from responses to questions the actual weight of their child, found that risk of overweight was significant greater among daughters compared to sons. On the other hand, perimeters of waist and hip and BMI percentiles were statistically associated with maternal perception of children's BMI categories. It can be seen in table 1 that the distribution of mean ranks trend of waist, hip, and BMI percentiles along perceived BMI categories suggests that mothers tend to classified correctly children's BMI.

As a result, when actual BMI categories and mother's perception of children's BMI categories were evaluated it can be observed that mothers tend to classified, in higher proportion, children in underweight (69.2\%) and normal weight $(77.4 \%)$ categories and in lower proportion children in overweight $(26.1 \%)$ and obesity $(31.8 \%)$ categories. These results are consistent with the findings of other authors in which parents tend to underestimate the weight of offspring with overweight and obesity [22,23]. When in this study that relationship was stratified by sex, the same tendency was found although maternal perception of girls BMI was higher in overweight category $(35.7 \%)$ in comparison with the corresponding measure among boys (11.1\%). For the contrary, obesity was perceived by mothers in higher proportion among boys than among girls. These results corroborate that mothers perceived in higher proportion overweight among girls and obesity among boys.

In spite of misclassifications between maternal perception of BMI categories and actual BMI categories, concordance index between these variables were relatively acceptable of 0.45 among global results and of 0.53 among men. However, concordance index among women was lower of 0.36 . For the contrary, Leppers et al. [20] found an inverse magnitude of concordance indexes evaluating actual BMI categories and mother's perception of children's BMI categories of 0.44 for girls and 0.36 for boys. These results suggest, in our study, that mothers better perceive the actual BMI categories among boys than among girls in the context of Piedras Negras City, probably as cultural issue in the Northern frontier of Mexico. Furthermore, this study shows that mother's perception of children's BMI categories had better concordance index with actual BMI categories of 0.45 compared with a previous study performed about self-perception of weight among school age children in Mexico whose result was of 0.30 [24]. These results suggest that mothers better perceive the actual weight of their children than the self-perception that children have of their own weight in Piedras Negras City.

Body size satisfaction perceived by mothers was as high as $68.9 \%$ that occurred mainly at expenses of the perception of children's normal weight. This is a high level of mothers' satisfaction with their children's weigh in Northern Mexico compared with Brazilian mothers that had lower level of satisfaction with their children's body size of 49.5 percent [25]. Although in our study dissatisfaction related to the prevalence of underestimation of children's weight was relatively low of 14.6 percent, their results were performed at expenses of perceived overweight and obesity categories in concordance with results provided by other authors $[22,25]$. On the other hand, overestimation of children's weight was performed, in our study, to expenses of mothers' perception of the low weight category. This result was consistent with the report of Warkentin et al. [26] in which study factors associated with parent underestimation of child's weight status were analyzed.

Finally, we found a significant relationship between body size satisfaction variable and indicators of body size as weight, waist, hip and BMI percentile indicating by their results that higher magnitudes of mean ranks were presented in the category of underestimation and lower magnitudes were in the category of overestimation regarding all indicators of body size analyzed. These results support the findings of our study in the sense of mothers tend to underestimate and overestimate their children weight.

\section{Conclusions}

This is a pilot study in which maternal perception of children's body weight showed a high magnitude of perceived children in normal

\begin{tabular}{|l|l|l|l|l|}
\hline Body size satisfaction & Weight (mean rank) & Waist (mean rank) & Hip (mean rank) & BMI Percentiles $¥$ (mean rank) \\
\hline Underestimation & 130.46 & 137.31 & 133.19 & 138.74 \\
\hline Same size & 80.44 & 78.53 & 79.79 & 79.46 \\
\hline Overestimation & 38.44 & 39.54 & 38.25 & 33.52 \\
\hline
\end{tabular}

Table 4: Relationship between the variable of body size satisfaction and indicators of actual body size among school children. $\neq \mathrm{p} \leq 0.001$, by Kruskal-Wallis test. 
Citation: Santos-Tonche M, Alonso-Tovar R, Parra-Ávila J, Portillo-Téllez MC, Mayo-Carrillo JF, et al. (2020) Maternal Perception of School-age Children's Weight in Piedras Negras, Coahuila. A Pilot Study. Int J Pediatr Neonat Care 6: 166. doi: https://doi.org/10.15344/2455-2364/2020/166

Page 5 of 5

weight and suggests that mothers perceive in higher proportion overweight among girls and obesity among boys. The relationship between maternal perception of children's body weight and indicators of children's body size suggests that mothers tend to classified correctly children's BMI. These suggestions were supported by concordance indexes between maternal perception of children's body size and actual BMI categories showing better concordance index among men than among women. Body size satisfaction perceived by mothers was high and occurred mainly at expenses of the perception of children's normal weight. Maternal dissatisfaction underestimates children's with overweight and obesity and over estimate those with low weight whose results were supported by the analysis of the children's body size variables.

\section{Competing Interests}

The authors declare that they have no competing interests.

\section{References}

1. Grogan S (1999) Body image. Understanding body dissatisfaction in men women and children. London/New York: Routledge.

2. Neagu A (2015) Body image: A thoretical framework. Proc Rum Acad 17: 29-38.

3. Childress AC, Brewerton TD, Hodges EL, Jarrel MP (1993) The Kids' Eating Disorder Survey (KEDS): A study of middle school students. J Am Child Adolesc Psychiatry 32: 843-850.

4. Collins ME (1991) Body figure perceptions and preferences among preadolescent children. Int J Eat Disord 10: 199-208.

5. Fallon $A E$, Rozin $P$ (1985) Sex differences in perceptions of desirable body shape. J Abnorm Psychol 94: 102.

6. Kostanski M, Gullone E (1999) Dieting and body image in the child's world: conceptualization and behavior. J Genet Psychol 160: 488-499.

7. Marković J, Votava-Raić, A, Nikolić S (1998) Study of eating attitudes and body image perception in the preadolescent age. Coll Antropol 22: 221 232.

8. Rolland K, Farnill D, Griffiths RA (1997) Body figure perceptions and eating attitudes among Australian schoolchildren aged 8 to 12 years. Int J Eat Disord 21: 273-278.

9. Truby H, Paxton SJ (2002) Development of the children's body image scale. Br J ClinPsychol 41: 185-203.

10. Baughcum AE, Chamberlin LA, Deeks CM, Powers SW \& Whitaker RC (2000) Maternal perceptions of overweight preschool children. Pediatrics 106 : 1380-1386.

11. Lopes L, Santos R, Pereira B, Lopes V (2013) Maternal perceptions of children's weight status. Child Care Health Dev 39: 728-736.

12. Ashraf H, Shamsi NI, Ashraf R (2017) Parental perception and childhood obesity: Contributors to incorrect perception. J Pak Med Assoc67: 214.

13. McDonald SW, Ginez HK, Vinturache AE, Tough SC (2016) Maternal perceptions of underweight and overweight for 6-8 years olds from a Canadian cohort: reporting weights, concerns and conversations with healthcare providers. BMJ Open 6: e012094.

14. Jeffery AN, Voss LD, Metcalf BS, Alba S, Wilkin TJ, et al. (2005) Parents' awareness of overweight in themselves and their children: cross sectional study within a cohort. BMJ 330: 23-24.

15. International Society for the Advancement of Kinanthropometry (2001) International standards for anthropometric assessment. Potchefstroom South Africa: ISAK.

16. Truby H, Paxton SJ (2008) The Children's Body Image Scale: Reliability and use with international standards for body mass index. Br J ClinPsychol 47: 119-124.

17. Romero F (2009) Tablas de percentiles de peso, talla y BMI. Programa para Windows.

18. Zclo M, Nieto J (2000) Epidemiology. Beyond the basics. Gaithersburg: Aspen Publishers Inc, USA.
19. Garcia ML, Crespo NC, Behar AI, Talavera GA, Campbell N, et al. (2019) Examining Mexican-Heritage mother's perception of their children's weight: comparison of silhouette and categorical survey methods. Child Obes 16: 44-52.

20. Leppers I, Tiemeier H, Swanson SA, Verhulst FC, Jaddoe VWV, et al. (2017) Agreement between weight status and perceived body size and the association with body size satisfaction in children. Obesity 25: 1956-1964.

21. Maynard LM, Galuska DA, Blanck HM, Serdula MK (2003) Maternal perception of weight status of children. Pediatrics 11: 1226-1231.

22. Lundahl A, Kidwell KM, Nelson TD (2014) Parental underestimates of child weight. A meta-analysis. Pediatrics 133: e689-703.

23. Lydecker J, Grilo C (2016) The apple of their eye: attitudinal and behavioral correlates of parents' perceptions of child obesity. Obesity (Silver Spring) 24: 1124-1131.

24. Uribe-Salas FJ, Portillo-TéllezMC, Parra-Ávila J, Hernández-Corral S, AlonsoTovar R, et al. (2018) Self-perception of weight in school-age children from PiedrasNegras, Coahuila, México (in Spanish). Bol Med Hosp Infant Mex 75: 366-372.

25. Pedroso J, Toral N, Gubert MB (2018) Maternal dissatisfaction with their children's body size in private schools in the Federal District, Brazil. PLoS One 13: e0204848.

26. Warkentin S, Mais LA, Latorre ML, Carnell M, Taddei JAAC, et al. (2018) Factors associated with parental underestimation of child's weight status. J Pediatr 94: 162-169. 